\section{Greenhouse Screening of Capsicum Accessions for Resistance to Green Peach Aphid (Myzus persicae)}

James D. Frantz

Department of Plant Breeding, Cornell University, Ithaca, NY 14853

\author{
Jeffrey Gardner and Michael P. Hoffmann \\ Department of Entomology, Cornell University, Ithaca, NY 14853
}

Molly M. Jahn' ${ }^{1}$

Department of Plant Breeding, Cornell University, Ithaca, NY 14853

Additional index words. insect resistance, insect tolerance, pepper, vegetable breeding, integrated pest management

Abstract. A greenhouse screen for resistance to green peach aphid (GPA) [Myzus persicae (Sulzer)] was done using 50 pepper (Capsicum spp.) accessions. There were significant differences among accessions for damage rating, number of aphids per plant and number of aphids per leaf. Leaf pubescence, the basis of a reported nonpreference resistance mechanism to green peach aphid infestation, failed to protect pepper accessions from GPA colonization and damage. Sources of resistance and tolerance to cotton aphid [Aphis gossypi (Glover)] supported high levels of green peach aphid infestation and exhibited considerable damage. Although no accessions provided strong resistance to aphid colonization evident by significantly reduced numbers of aphids, several commercial varieties and sources of virus resistance exhibited strong tolerance to GPA, evident as reduced damage. Tolerant varieties could be an important component in integrated pest management of green peach aphid.

The green peach aphid (GPA) is an important pest of peppers in the northeastern U.S.As a direct pest of pepper plants, high populations of GPA can cause chlorosis, necrosis, wilting, stunting, flower and fruit abortion, leaf distortion and defoliation. In addition, aphid honeydew excretions can be accompanied by the growth of sooty mold, contaminating fruit and reducing the photosynthetic capability of plants. GPA is even more important as an indirect pest, vectoring plant viruses such as cucumber mosaic virus (CMV), tobacco etch virus (TEV), pepper mottle virus (PepMoV) and potato virus Y (PVY). In New York, annual infestation of GPA affects $\geq 75 \%$ of the pepper acreage, with yield losses as high as $50 \%$ when combined with losses due to virus damage.

Capinara reviewed the life cycle of green peach aphid. GPA eggs generally overwinter on Prunus spp. After several generations of growth on the overwintering host during spring, green peach aphids move onto summer hosts, including pepper. As they disperse, winged females deposit a few offspring on a plant, then move on. These offspring are wingless females that reproduce parthenogenetically at high rates, each giving birth to between 30 to

Received for publication 6 May 2003. Accepted for publication 29 Sept. 2003. We would like to thank the Asian Vegetable Research and Development Center for cotton aphid resistant germplasm. This study was funded in part by the Cornell University Vegetable Breeding Institute and USDA IFAFS Award No. 2001-52100-11347.

${ }^{1}$ To whom reprint requests should be addressed; e-mailmmj9@cornell.edu. resistance in the pest combined with negative impacts on natural enemy populations.

Aphid-resistant pepper varieties could offer a potential means of control that would complement predation by natural enemies while reducing the need for insecticide sprays. There is no genetic resistance to GPA used in commercial pepper varieties, but resistance has been described in Capsicum pubescens. The proposed resistance mechanism in this study was antixenosis (nonpreference) due to extremely pubescent leaves. Unfortunately, there are sexual barriers between this species and commercially grown peppers, most of which are $C$. annuum. There have been no other published studies describing resistance to GPA in pepper.

Pepper accessions have been screened for resistance to the cotton aphid (CA), revealing several sources of resistance/tolerance. Three resistant accessions were $C$. baccatum, which can be crossed to $C$. annuum with some difficulty. Other resistant accessions were $C$. annuum.

One objective of our study was to screen pubescent-leaved accessions for resistance to GPA. Another objective was to screen CA resistant/tolerant pepper accessions for resistance to GPA, defined as reduced damage or insect counts. The final objective was to screen a selection of commercial pepper varieties and sources of pathogen resistance for resistance to GPA infestation. Results from these studies will provide essential information to initiate a breeding program for resistance or tolerance to GPA in pepper. week under peak temperatures. High population numbers and deterioration of host plants induce the production of winged aphids for a new round of dispersal.

In many cases, natural enemies of aphids keep GPA numbers in check. Rapidly increasing aphid populations are most commonly observed after broad-spectrum insecticides, used to control other insect pests such as European corn borer (Ostrinia nubilialis), have wiped out natural enemy populations. Chemical control of GPA is usually inadequate due to insecticide

\section{Materials and Methods}

Plant material and culture. In total, 50 pepper accessions were screened in this study. Accessions and seed sources are listed in Table 1. Plants were seeded on 21 Apr. 1999 into commercial peat potting mix (Premier ProMix, Dorval, Quebec) and grown under 1000 $\mathrm{W}$ halogen lights in the Cornell University Insectary greenhouses, Ithaca, N.Y., result-

Table 1. Sources of Capsicum accessions screened for resistance to green peach aphid.

\begin{tabular}{ll}
\hline Source and location & Accession \\
\hline Agway Inc., Syracuse, N.Y. & Cal Wonder \\
Asgrow Seed Co., San Juan Bautista, Calif. & NuMex RNaky \\
AVRDC, Taiwan & PBC 18, PBC 30, PBC 81, PBC 84, PBC 100, PBC 151, \\
& PBC 322 (Tabasco), PBC 345 (Serrano Vera Cruz), \\
& PBC 519, PBC 681 (Early Jalapeno), \\
& PBC 726, PBC 738, PBC 897, PBC 1351, \\
& PBC 1426 (Rocoto), PBC 1489 (Rocoto Yellow) \\
CalCompack Foods, King City, Calif. & CalCompack \\
Cornell University, Ithaca, N.Y. (M. Jahn) & PI 159234-2, PI 159234-3 \\
Cornell University, Ithaca, N.Y. (T. Thorup) & Red Scotch Bonnet, Yellow Scotch Bonnet \\
INIA, Mexico (J. Laborde) & BG 2814-6 \\
INRA, France (A. Palloix) & Perennial \\
NPGS, Griffin, Ga. & PI 159236-1 \\
Rogers Seed Co., Naples, Fla. & Criollos de Morelos \\
Stokes Seeds, Buffalo, N.Y. & Ace, Camelot, Jupiter, Merlin \\
Tomato Growers Supply Co., Fort Myers, Fla. Ancho 101, Banana Supreme, Commandant, & Charleston Hot, Corno di Toro, Cubanelle PS, \\
& Habanero, Hungarian Wax, \\
& Long Red Slim Cayenne, Large Red Thick Cayenne, \\
& Paprika Supreme, Pasilla Bajio, Pepperoncini, \\
& Peto Wonder, Pimento L, Rocoto, Serrano, \\
& Super Red Pimento, Super Cayenne II \\
\hline
\end{tabular}


ing in an illumination intensity of about 150 $\mu \mathrm{mol} \cdot \mathrm{m}^{-2} \cdot \mathrm{s}^{-1}$. After transplanting on 2 June into 200-mm-diameter pots (Kord Products, Toronto, Ontario), plants were grown in the greenhouse without supplemental lighting. Six plants per accession (300 plants total) were arranged in a completely randomized design with one plant per replication. Plants were spaced $26 \mathrm{~cm}$ apart within rows $36 \mathrm{~cm}$ apart on greenhouse benches. Temperatures were maintained between 22 and $32^{\circ} \mathrm{C}$. Plants were fertilized by watering with a Peters 20-20-20 plant food (Scotts, Marysville, Ohio) once per week.
Aphid colony establishment. GPA, positively identified from an infested pepper leaf in the Cornell Insectary greenhouse, were used to infest several plants of the susceptible bell pepper cultivar Capistrano (PetoSeed, Woodland, Calif.). The aphid colony was kept in a growth chamber for $30 \mathrm{~d}$ under $16 \mathrm{~h}$ of maximum illumination at $25{ }^{\circ} \mathrm{C}$ and $8 \mathrm{~h}$ of darkness at 22 ${ }^{\circ} \mathrm{C}$ until adequate numbers were available to infest the 50 accessions.

Infestation and evaluation. On 7 July 1999, 10 aphids were transferred to young, fully expanded leaves of each plant using a small diameter camelhair brush. This method

Table 2. Response of Capsicum accessions to artificial infestation with green peach aphid.

\begin{tabular}{|c|c|c|c|c|c|c|}
\hline \multirow[b]{2}{*}{ Accession } & \multicolumn{2}{|c|}{ Damage rating } & \multicolumn{2}{|c|}{ Aphids per plant } & \multicolumn{2}{|c|}{ Aphids per leaf } \\
\hline & Rank & Mean & Rank & Mean & Rank & Mean \\
\hline Paprika Supreme & 1 & $0.0 \mathrm{a}^{\mathrm{z}}$ & 44 & 2517 mnop & 18 & 33.0 abcdefghi \\
\hline Pasilla Bajio & 2 & $0.5 \mathrm{ab}$ & 2 & $433 \mathrm{ab}$ & 11 & 29.9 abcdefgh \\
\hline CalCompack & 2 & $0.5 \mathrm{ab}$ & 7 & 858 abcdef & 9 & 26.7 abcdef \\
\hline Hungarian Wax & 2 & $0.5 \mathrm{ab}$ & 8 & 942 abcdef & 6 & 24.7 abcde \\
\hline Banana Supreme & 2 & $0.5 \mathrm{ab}$ & 9 & 958 abcdefg & 1 & $15.5 \mathrm{a}$ \\
\hline $159234-2^{y}$ & 2 & $0.5 \mathrm{ab}$ & 19 & 1432 defghijk & 21 & 35.2 abcdefghi \\
\hline Pimento L & 2 & $0.5 \mathrm{ab}$ & 33 & 1850 hijklmn & 35 & 47.3 efghijk \\
\hline Super Red Pimento & 8 & $0.8 \mathrm{abc}$ & 29 & 1708 fghijklm & 28 & 37.7 abcdefghi \\
\hline Ancho 101 & 8 & $0.8 \mathrm{abc}$ & 41 & $2250 \mathrm{klmno}$ & 13 & 30.4 abcdefgh \\
\hline BG 2814-6y & 10 & $1.0 \mathrm{abcd}$ & 14 & 1117 bcdefghi & 2 & $17.4 \mathrm{ab}$ \\
\hline $159234-3^{y}$ & 10 & $1.0 \mathrm{abcd}$ & 16 & 1317 cdefghij & 27 & 37.5 abcdefghi \\
\hline Perennial $^{y}$ & 10 & $1.0 \mathrm{abcd}$ & 20 & 1475 defghijk & 10 & 28.9 abcdefg \\
\hline Large Red Thick Cayenne & 10 & $1.0 \mathrm{abcd}$ & 35 & 1950 ijklmno & 8 & 26.5 abcdef \\
\hline Long Red Slim Cayenne & 10 & $1.0 \mathrm{abcd}$ & 45 & 2583 nop & 16 & 32.0 abcdefghi \\
\hline $159236-1^{\mathrm{y}}$ & 15 & 1.2 bcde & 4 & $642 \mathrm{abcd}$ & 19 & 33.8 abcdefghi \\
\hline Pepperoncini & 15 & 1.2 bcde & 31 & 1817 ghijklmn & 30 & 38.8 bcdefghij \\
\hline Jupiter & 17 & 1.3 bcdef & 5 & 767 abcde & 43 & 52.7 hijkl \\
\hline NuMex RNaky & 18 & 1.5 bcdefg & 22 & 1533 efghijk & 24 & 37.1 abcdefghi \\
\hline Ace & 18 & 1.5 bcdefg & 26 & 1642 fghijkl & 15 & 31.7 abcdefghi \\
\hline Super Cayenne II & 18 & 1.5 bcdefg & 39 & 2233 klmno & 14 & 30.5 abcdefgh \\
\hline $\operatorname{PBC} 84^{x}$ & 21 & 1.8 cdefg & 43 & 2450 lmnop & 46 & $64.0 \mathrm{klm}$ \\
\hline Corno di Toro & 21 & 1.8 cdefg & 49 & $3183 \mathrm{pq}$ & 39 & 49.0 fghijkl \\
\hline Charleston Hot $^{\mathrm{w}}$ & 21 & 1.8 cdefg & 50 & $3700 \mathrm{q}$ & 23 & 36.3 abcdefghi \\
\hline Cal Wonder & 24 & 2.0 defgh & 3 & $522 \mathrm{abc}$ & 22 & 35.8 abcdefghi \\
\hline $\operatorname{PBC} 18^{x}$ & 24 & 2.0 defgh & 17 & 1325 cdefghij & 5 & $23.5 \mathrm{abcd}$ \\
\hline Merlin & 26 & 2.2 efghi & 35 & 1950 ijklmno & 45 & $61.4 \mathrm{jklm}$ \\
\hline PBC 1426 (Rocoto) $)^{v}$ & 27 & 2.3 fghij & 15 & 1267 bcdefghij & 42 & 51.4 ghijkl \\
\hline Serrano $^{v}$ & 27 & 2.3 fghij & 21 & 1508 efghijk & 3 & $20.4 \mathrm{abc}$ \\
\hline Peto Wonder & 27 & 2.3 fghij & 24 & 1633 fghijkl & 41 & 50.9 ghijkl \\
\hline Habanero & 27 & 2.3 fghij & 27 & 1650 fghijkl & 17 & 32.9 abcdefghi \\
\hline PBC 322 (Tabasco) & 27 & 2.3 fghij & 46 & 2733 op & 26 & 37.3 abcdefghi \\
\hline PBC 681 (Early Jalapeno) $^{u}$ & 27 & 2.3 fghij & 46 & 2733op & 37 & 48.4 fghijkl \\
\hline Criollos de Morelos ${ }^{\mathrm{v}}$ & 33 & 2.4 fghij & 12 & 1060 abcdefgh & 4 & $20.6 \mathrm{abc}$ \\
\hline PBC 1489 (Rocoto Yellow) $^{v}$ & )$^{\mathrm{v}} 34$ & 2.5 ghijk & 18 & 1350 cdefghij & 40 & 49.2 fghijkl \\
\hline Commandant & 34 & 2.5 ghijk & 24 & 1633 fghijkl & 44 & $53.8 \mathrm{ijkl}$ \\
\hline Camelot & 34 & 2.5 ghijk & 48 & 2783 op & 47 & $71.1 \mathrm{~lm}$ \\
\hline PBC 345 (Serrano Vera Cruz) & )$^{v} 37$ & 3.0 hijkl & 13 & 1075 abcdefgh & 7 & 24.9 abcde \\
\hline $\mathrm{PBC} 100^{\mathrm{t}}$ & 37 & 3.0 hijkl & 31 & 1817 ghijklmn & 12 & 30.3 abcdefgh \\
\hline PBC $726^{u}$ & 37 & 3.0 hijklm & 38 & 2117 jklmno & 20 & 34.9 abcdefghi \\
\hline PBC $30^{x}$ & 40 & $3.2 \mathrm{ijklm}$ & 39 & 2233 klmno & 29 & 38.4 abcdefghij \\
\hline Cubanelle PS & 41 & $3.3 \mathrm{jklm}$ & 23 & 1567 efghijk & 34 & 45.5 defghijk \\
\hline Rocoto $^{v}$ & 41 & $3.3 \mathrm{jklm}$ & 30 & 1800 ghijklmn & 32 & 42.1 cdefghijk \\
\hline Red Scotch Bonnet & 43 & $3.5 \mathrm{klm}$ & 42 & 2283 klmno & 49 & 104.0 no \\
\hline Yellow Scotch Bonnet & 44 & $3.8 \mathrm{~lm}$ & 35 & 1950 ijklmno & 50 & $115.4 \mathrm{o}$ \\
\hline PBC $519^{v}$ & 45 & $4.0 \mathrm{lmn}$ & 10 & 980 abcdefg & 33 & 44.8 defghijk \\
\hline PBC $897^{t}$ & 45 & $4.0 \mathrm{lmn}$ & 27 & 1650 fghijkl & 31 & 38.9 bcdefghij \\
\hline PBC 738 & 45 & $4.0 \mathrm{lmn}$ & 33 & 1850 hijklmn & 38 & 48.9 fghijkl \\
\hline $\mathrm{PBC} 1351^{\mathrm{u}}$ & 48 & $4.2 \mathrm{mn}$ & 6 & 850 abcdef & 25 & 37.2 abcdefghi \\
\hline $\mathrm{PBC} 151^{\mathrm{u}}$ & 49 & $5.0 \mathrm{n}$ & 1 & $255 \mathrm{a}$ & 36 & 48.0 fghijk \\
\hline $\mathrm{PBC} 81^{\mathrm{u}}$ & 49 & $5.0 \mathrm{n}$ & 11 & 983 abcdefg & 48 & $83.7 \mathrm{mn}$ \\
\hline $\operatorname{LSD}(P=0.05)$ & & 1.1 & & 859 & & 23.0 \\
\hline
\end{tabular}

${ }^{\text {z } M e a n ~ s e p a r a t i o n ~ i n ~ c o l u m n s ~ b y ~ F i s h e r ' s ~ p r o t e c t e d ~ L S D ~ t e s t ~ a t ~} P=0.05$.

${ }^{\mathrm{y}} \mathrm{CMV}$ or potyvirus resistant.

${ }^{\mathrm{x}}$ Cotton aphid resistant.

wematode resistant.

'Pubescent.

"Cotton aphid tolerant.

'Cotton aphid susceptible. was used to ensure equal pest pressure across accessions and to prevent escapes. Six weeks after infestation, all accessions were assessed for aphid colonization and damage. Visual estimation was used to generate aphid per plant values. To generate guidelines for visual estimates, aphid counts were first done on representative pepper leaves. Aphids per plant values were then derived from cumulative visual estimates from each leaf of a plant. For consistency, one observer did visual estimation across accessions. Aphids per leaf values represent aphid per plant values divided by total leaf counts from each plant. Length and width measurements from median-sized leaves of each plant were used to calculate relative leaf size.

Individual ratings were made for leaf distortion, chlorosis, necrosis, honeydew, and stunting using a 0 to 5 scale, where $0=$ none to very mild, $1=$ mild, $2=$ moderate, $3=$ moderately severe, $4=$ severe , and $5=$ very severe. Damage rating was determined according to the same scale after visual inspection of the combined effects of leaf deformation, chlorosis, necrosis, flower and fruit abortion, defoliation, stunting, honeydew, and sooty mold accumulation. Analysis of variance, Fisher's protected LSD test, and Pearson correlations were performed using Minitab 13 statistical software (Minitab, State College, Pa.)

\section{Results}

There were significant differences among pepper accessions for all three measures of GPA infestation (Table 2). Mean damage ratings ranged from 0 to 5 among the 50 accessions. The mean number of aphids per plant ranged from 255 to 3700 , while the mean number of aphids per leaf ranged from 15.5 to 115.4 . Based on the high populations of aphids supported per plant and per leaf, it was evident that none of the accessions in this screen can be considered highly resistant to GPA colonization. Even accessions showing the lowest levels of infestation exceeded recommended chemical control action thresholds of 10 aphids per leaf.

Damage ratings were useful as a means to measure the relative tolerance of entries for GPA infestation. Damage rating was not correlated with aphids per plant but was positively correlated with aphids per leaf (Table 3 ). This indicated that aphids per leaf was a better indicator of potential damage than aphids per plant. Damage rating was negatively correlated with leaves per plant. This was due in some part to the effects of defoliation on highly damaged plants. As expected, damage rating was positively correlated with leaf distortion, defoliation, chlorosis, and necrosis. Honeydew production was not correlated with damage rating due to the fact that it was generally not considered damaging unless accompanied by sooty mold. Stunting was not correlated with damage rating, because in many cases it could not be attributed only to aphid infestation.

The number of aphids per plant was positively correlated with aphids per leaf, but was not a very informative measure of infestation 
Table 3. Correlation coefficients between variables related to green peach aphid infestation and damage.

\begin{tabular}{|c|c|c|c|}
\hline Parameter & $\begin{array}{c}\text { Damage } \\
\text { rating }\end{array}$ & $\begin{array}{c}\text { Aphids } \\
\text { per } \\
\text { plant }\end{array}$ & $\begin{array}{c}\text { Aphids } \\
\text { per } \\
\text { leaf }\end{array}$ \\
\hline Damage rating & --- & $-0.010^{\mathrm{NS}}$ & $0.407^{* *}$ \\
\hline Aphids per plant & $-0.010^{\mathrm{Ns}}$ & --- & $0.256^{* *}$ \\
\hline Aphids per leaf & $0.407^{* *}$ & $0.256^{* *}$ & --- \\
\hline Leaves per plant & $-0.364^{* *}$ & $0.561^{* *}$ & $-0.389^{* *}$ \\
\hline Leaf size & $0.212^{* *}$ & $0.118^{\mathrm{Ns}}$ & $0.545^{* *}$ \\
\hline Leaf distortion & $0.636^{* *}$ & $-0.175^{*}$ & $0.241^{* *}$ \\
\hline Defoliation & $0.654^{* *}$ & $-0.229^{* *}$ & $0.293^{* *}$ \\
\hline Chlorosis & $0.610^{* *}$ & $-0.057^{\mathrm{Ns}}$ & $0.259^{* *}$ \\
\hline Necrosis & $0.644^{* *}$ & $-0.095^{\mathrm{Ns}}$ & $0.297^{* *}$ \\
\hline Honeydew & $0.102^{\mathrm{Ns}}$ & $0.555^{* *}$ & $0.342^{* *}$ \\
\hline Stunting & $0.075^{\mathrm{Ns}}$ & $-0.471^{* *}$ & $0.075^{\mathrm{Ns}}$ \\
\hline
\end{tabular}

Ns,,$* * *$ Nonsignificant at $P \leq 0.01$ ) or significant at $P>0.01$ or 0.001 , respectively.

due to a negative correlation with defoliation and plant stunting (Table 3). Varying degrees of defoliation and stunting affected many of the more promising accessions in this category, resulting in fewer numbers of leaves. Indeed, there was a positive correlation between aphids per plant and leaves per plant. Honeydew production was positively correlated with aphids per plant. Aphids per leaf was positively correlated with aphids per plant, damage rating and associated damage measures such as leaf distortion, defoliation, chlorosis, and honeydew. It was also positively correlated with leaf size and negatively correlated with leaves per plant. This is consistent with the negative correlation of leaves per plant and leaf size $(R=-0.27)$. Aphids per leaf was not correlated with plant stunting.

The pubescent leaves of $C$. pubescens (rocoto) peppers are proposed to provide resistance to GPA through a nonpreference mechanism. The three rocoto entries in this screen were highly infested with aphids (Table 2), ranging from 42.1 to 51.4 aphids per leaf (rank 32 to 42) and with damage ratings ranging from 2.3 to 3.3 (rank 27 to 41 ). There were no significant differences between the three accessions for any of the variables. Serrano peppers are $C$. annuum varieties with pubescent leaves. Three of the four serrano accessions ranked high for aphids per leaf with 'Serrano', 'Criollos de Morelos', and 'Serrano Vera Cruz' ranking $3^{\text {rd }}, 4^{\text {th }}$, and $7^{\text {th }}$ respectively. At least part of this was due to small leaf size. Another serrano accession, PBC 519, ranked $33^{\text {rd }}$ for aphids per leaf. Defoliation, leaf distortion, chlorosis and necrosis caused all serrano accessions to rank low in terms of damage rating. Their rankings ranged from 27 to 45 . Based on the performance of rocoto and serrano peppers in this screen, it appears that leaf pubescence does not provide any significant deterrence to GPA colonization and damage.

Several sources of CA-resistance/tolerance were included in the screen. Three tolerant accessions, PBC 81, PBC 151, and PBC 1351, were from the species $C$. baccatum. These three entries ranked last for damage rating in the trial even though they ranked high for aphids per plant (Table 2). This was due to very severe defoliation among all three accessions. Aphid per leaf ranks ranged between 25 and 48 . Three tolerant $C$. annuum accessions, PBC 681 (Early Jalapeno), PBC 726 and PBC 738 performed poorly in all three resistance categories. The plants suffered from severe defoliation, leaf deformation, chlorosis and necrosis. Their damage rankings placed them $27^{\text {th }}, 37^{\text {th }}$, and $45^{\text {th }}$ respectively. $C$. annuum accessions $\mathrm{PBC}$ 18, PBC 30, and PBC 84, all characterized as resistant to $\mathrm{CA}$, varied in their response to GPA but generally supported high levels of infestation. Damage rankings were 24, 40, and 21 ; aphids per plant rankings were 17,39 , and 43; aphid per leaf rankings were 5, 29 and 46, respectively. Two accessions described as $\mathrm{CA}$ susceptible, PBC 100 and PBC 897, ranked $37^{\text {th }}$ and $45^{\text {th }}$ for damage rating. Among the nine accessions characterized as CA resistant or tolerant tested in this study, only PBC 84 had a significantly better damage rating than PBC 100, while only PBC 84 and PBC 18 had significantly better damage ratings than PBC 897. Based on these results, it is apparent that resistance and tolerance to CA does not extend to GPA.

PI 159234-2 and PI 159234-3 are lines developed by three rounds of self-pollination of two plants of the same $C$. chinense plant introduction carrying the recessive potyvirus resistance gene, pvrl. Because the lines are essentially identical, they provide an internal check. There was no significant difference in damage rating ( 0.5 vs. 1.0$)$, aphids per plant (1432 vs. 1317) or aphids per leaf(35.2 vs. 37.5) between the two lines, indicating a good degree of consistency in infestation and damage rating across the trial. Rankings for the two entries were 2 and 10 for damage rating, 19 and 16 for aphids per plant, and 21 and 27 for aphids per leaf, respectively. Another $C$. chinense accession, PI 159236-1, carries pvrl along with the $T s w$ gene for resistance to tomato spotted wilt virus. Although 159236-1 ranked high for aphids per plant, this was partly due to stunting, which severely reduced the number of leaves. The ranking for aphids per leaf was 19 , while the overall damage ranking was 15 .

Other sources of disease resistance widely used in pepper were also tested for resistance to aphid infestation. Two sources of CMV resistance, BG 2814-6 and Perennial, had damage ratings of 1.0 (ranking $10^{\text {th }}$ ) while ranking $2^{\text {nd }}$ and $10^{\text {th }}$ for aphids per leaf respectively. They were not significantly different from the highest rating in either category. They ranked $14^{\text {th }}$ and $20^{\text {th }}$ for aphids per plant. 'Charleston Hot' is a nematode resistant cultivar derived from an open-pollinated pepper containing one dominant and one recessive gene for resistance to nematode infection. In tomato, the dominant $M i$ allele confers resistance to both root knot nematodes and the potato aphid (Macrosiphum euphorbiae), but does not control GPA. In our screen, 'Charleston Hot' had the highest overall level of aphids per plant with 3700 per plant and ranked $23^{\text {rd }}$ for aphids per leaf with 36.3 per leaf. The damage rating (1.8) was $21^{\text {st }}$.

Several commercial cultivars ranked the highest for damage rating. 'Paprika Supreme' was the least damaged entry. It set many normally developed fruits and had no signs of stunting, necrosis, chlorosis, leaf deformation, or defoliation. There was a fair amount of honeydew, but damage due to sooty mold was low. 'Pasilla Bajio' showed very little damage due to aphids, but a large amount of plant stunting made it difficult to rate the development of the plants. The paprika cultivar 'CalCompack' showed a small amount of stunting, but generally exhibited normal development and little evidence of aphid damage. 'Hungarian Wax' also developed normally, set many fruits, and showed no signs of damage beyond a minor amount of stunting. 'Banana Supreme' was very productive with no stunting and showed very little damage of any kind outside of a small amount of sooty mold. This cultivar also had the lowest number of aphids per leaf (15.5), and would therefore be considered the most resistant entry in the screen. 'Pimento L' had a high number of aphids per leaf (47.3) but showed very good tolerance, including normal development, good fruit set and virtually no damage beyond a small amount of sooty mold. Another pimento, 'Super Red Pimento', performed nearly as well, suffering only small amount of chlorosis and flower abortion. 'Ancho 101' showed good vigor, set many fruits, and showed very little aphid damage. The varieties 'Large Red Thick Cayenne' and 'Long Red Slim Cayenne' showed normal development and produced large numbers of normal fruit. They suffered mainly from large amounts of honeydew and minor amounts of sooty mold.

\section{Discussion}

Based on the results of a severe screen designed to apply equal pest pressure across all entries, it is apparent that resistance/tolerance to CA does not extend to the GPA. The highest ranked CA resistant accession (PBC 84) had a significantly higher damage rating than the top seven accessions in that category, while the four lowest ranking accessions for damage rating were all CA resistant and tolerant. This type of species-specificity for aphid resistance was also seen for the $M i$ locus in tomato, as mentioned above. Although suggested by previous authors as a nonpreference factor in aphid resistance, pubescence did not protect plants from high levels of aphids and aphid-related damage in this screen. It is likely that by placing aphids on the leaves directly that we bypassed any type of nonpreference mechanism, although aphids were not contained on the plants and were free to move off of pubescent accessions onto neighboring plants. In contrast, sources of plant virus resistance we tested performed 
relatively well with respect to overall aphid damage. Some of these accessions have been found to have resistance to multiple pathogens, so it is possible that they also harbor some degree of insect resistance and tolerance. We also demonstrated that nematode (Meloidogyne spp.) resistance in Charleston Hot does not have any positive effect on resistance to GPA.

Although no accessions tested in this screen showed strong resistance to aphid colonization, there appeared to be some promising levels of tolerance to aphid infestation even among commercial cultivars that could be used in breeding programs. High levels of tolerance to western flower thrips (Frankliniella occidentalis) were likewise found in commercial peppercultivars. Plant stunting and defoliation, however, were the most confounding factors in terms of relating aphid colonization to overall damage. Observations made at earlier time points in the infestation process may have given a clearer idea of the colonization level of certain genotypes that were susceptible to defoliation. Observation at earlier time points would also help detect whether stunting was a response to aphid infestation or to other stimuli. Utilization of a damage rating helped mitigate these complications to some degree.

Further testing using more elaborate experimental designs corroborated by results in field studies will be required to determine the most useful accessions for breeding for reduced damage from GPA infestation and to clarify the mechanism(s) involved. It is possible that different moderately resistant accessions could be combined to generate a genotype showing transgressive segregation for less damage if the genetic systems governing the responses we observed in this study are different. It view of these results, it would also be advisable to undertake a larger scale search for tolerance/resistance to GPA because no clear highly resistant accession was identified in this study. Increased tolerance/resistance to GPA in commercial varieties could reduce the need for insecticide application and, even at moderate levels could be compatible with integrated pest management systems that promote control of aphid populations by natural enemies.

\section{Literature Cited}

Bosland, P.W. and J.J. Ellington. 1996. Comparison of Capsicum annuum and C. pubescens for antixenosis as a means of aphid resistance. Hortscience 31:1017-1018.

Boucher, J. 1999a. Pepper IPM: Aphids. 5 Mar. 2003. www.hort.uconn.edu/ipm/veg/htms/ aphids.htm.

Boucher, J. 1999b. Pepper IPM: Aphids and viruses. 18 Mar. 2003. www.hort.uconn.edu/ipm/veg/ htms/pepvrus.htm.

Capinera, J.L. 2001. Handbook of vegetable pests. Academic Press, San Diego, Calif.

Dukes, P.D. and R.L. Fery. 1997. 'Charleston Hot', a southern root-knot nematode-resistant, yellow- fruited cayenne pepper with a compact plant habit. Hortscience 32:947-948.

Fery, R.L. and J.M. Schalk. 1991. Resistance in pepper (Capsicum annuиm L.) to western flower thrips [Frankliniella occidentalis (Pergande)]. Hortscience 26:1073-1074.

Goggin, F.L., V.M. Williamson, and D.E. Ullman. 2001. Variability in the response of Macrosiphum euphorbiae and Myzus persicae (Hemiptera: Aphididae) to the tomato resistance gene $\mathrm{Mi}$. Environ. Entomol. 30:101-106.

Hazzard, R.V. 2000. Insect management in peppers. 5 Mar. 2003. www.umassvegetable.org/ soil_crop_pest_mgt/peppers/insect_management_in_peppers.html.

Stivers, L. 1999. Crop profiles for peppers of New York. 24 May 2003. www.pestdata.ncsu.edu/ cropprofiles/docs/nypeppers.html.

Talekar, N.S. and T. Berke. 1998. Breeding for pest resistance/tolerance in pepper, p. 165-168. In: Xth EUCARPIA Meeting on Genetics and Breeding of Capsicum and Eggplant, Avignon, France.

University of Connecticut Cooperative Extension System. 2002. New England vegetable management guide. Univ. Conn. Coop. Ext. System, Storrs.

Vos, P., G. Simons, T. Jesse, J. Wijbrandi, L. Heinen, R. Hogers, A. Frijters, J. Groenendijk, P. Diergaarde, M. Reijans, O.J. Fierens, M. de Both, J. Peleman, T. Liharska, J. Hontelez, and M. Zabeau. 1998. The tomato Mi-1 gene confers resistance to both root-knot nematodes and potato aphids. Nature Biotechnol. 16:1365. 